\title{
Demand Curve and Bliss Point
}

\author{
Guangping Hui, Changjun $\mathrm{Wu}^{*}$ \\ School of Economic and Management, Nanjing University of Science and Technology, China \\ *Changjun Wu, master,634004718@qq.com
}

\begin{abstract}
:
The law of demand is the most important basic theory in economics. But lots of scholars have different opinions on this theory, and the controversy of the law of demand that some scholars believe that there is a positive correlation between demand and price, but other scholars insist that demand and price have a negative relationship has been continuing. In this paper, we rediscover the rational person hypothesis and the law of demand based on the previous studies. The research findings deepen the understanding of the law of demand and the rational man hypothesis, and provide a powerful explanation to Giffen phenomenon.
\end{abstract}

Key words: hypothesis of rational man; bliss point; the law of demand; giffen phenomenon

\section{Introduction}

At the beginning of the 21st century, there was a dispute about the trend of demand curve in China. Some scholars believe that the demand curve is upward sloping, which means that there is a negative correlation between demand and price. The reason that supports their view that the demand theorem does not hold is the Giffen goods, which is also called the Giffen phenomenon, and the representative scholars are Wang Zeke, Wang Dingding. While lots of scholars (e.g. Zhang Wuchang ${ }^{1}$ et al) believe that the demand curve slopes downward, and the law of demand is completely established. They hold the view that the condition of the law of demand, the price of goods being the only effects of the influencing factors of demand, has changed in the Giffen phenomenon. This controversy is very intense, even a lot of ironic language appearing in their papers. For example, Wang Zeke $e^{2}$ said that Zhang Wuchang is well-known in college, which is a Giffen phenomenon in economic education. Is there a special case of the demand theorem? Why does the demand curve show a different trend? This paper will restudy and interpret the law of demand and Giffen phenomenon based on the premise of the law of demand, hypothesis of rational man and bliss point.

\section{Overview of hypothesis of rational man, bliss point, and the law of demand}

\subsection{Hypothesis of rational man}

The current mainstream scholars on the rational person hypothesis have the following several views. Firstly, the people are egoistic. Zhang Wuchang pointed out that the second basic 
assumption of economics is that any behavior of each person is the egoistic. Secondly, people

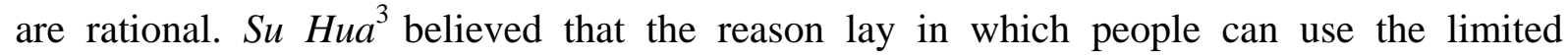
knowledge to do their choice that reach utility maximization. Maximum utility is not limited to the economic benefits, but also includes the economy, moral, law, hobby and other aspects of utility maximization comprehensively. Thirdly, rational person has information completeness. Zhu Chengquan and Ding Yuhai ${ }^{4}$ considered that the behavior of the individual was determined to be a rational behavior and individuals can obtain enough information about the surrounding environment according to the information obtained by the individual. This requires economic participants with complete information, which is far from the actual situation. Forth is the limited rationality. Yaniv Hanoch ${ }^{5}$ believed that personal preference was not always absolutely stable and consistent, and would change with the change of environment. The limited rationality is the incomplete information on the hypothesis of rational man. Compared with fully rational point of view, it is more close to the reality of human behaviors.

In short, rational people are able to make their own choices in economic utility maximization, according to their own standards of measurement and decision-making thinking with the prevailing environment and known information. Therefore, the following discussion and analysis is based on this definition.

\subsection{Bliss point}

When most of the scholars in relation to the rational economic participant (the rational person) concept, they often ignore the rational people with bliss point. In the economic field, we rarely see the article of Bliss point being discussed or researched. In the current textbooks, Hal $R$ Varian $^{6}$ have made a brief introduction. As shown in Figure 1, it assumes there are two kinds of commodities, chocolate cake and ice-cream. You can choose a proper amount of chocolate cake and ice cream every week, and less than that amount it will make you uncomfortable, but more than that it also makes you uncomfortable. Therefore, what is interesting is that what people have is less than what they want. The choices that people care about are the one that we care about. The appropriate number refers to a number of chocolate and ice cream satisfies the consumer's utility. More or less than this number will reduce consumer's utility. So the appropriate number is the bliss point.

Fig.1. (a), if the increase in consumer income or the decline in the price of commodity $\mathrm{X}_{1}$ and $\mathrm{X}_{2}$, the income effect of consumer would increase. In this case, the consumer will increase the purchase of two kinds of goods. Due to the increase in the amount of purchase, consumers' utility will be increased. When the amount of purchase increases to a certain amount, the utility will reach the maximum. At this point, the utility will not be increased but only be decreased whatever the purchase amount being increased. Then, the optimal choice of consumers is the utility of the maximum point.

Fig.1. (b), the number of $\mathrm{X}_{1}$ increases, the utility of consumer will be increased. When $\mathrm{X}_{1}$ is 
equal to $\mathrm{X}_{10}$, the consumer's utility reaches the maximum $\mathrm{U}_{\mathrm{m}}$. When $\mathrm{X}_{1}$ is equal to $\mathrm{X}_{12}$, the utility(Us) of the $X_{12}$ point is equal to the utility of the $X_{11}$. When there is the ability to pay the amount of $\mathrm{X}_{12}$, the best choice for consumers is the utility maximum point $\left(\mathrm{X}_{10}, \mathrm{U}_{\mathrm{m}}\right)$. If people can only get the Us of the utility, then the best choice for them is $\left(U_{s}, X_{11}\right)$, rather than $\left(\mathrm{X}_{11}, \mathrm{U}_{\mathrm{s}}\right)$. In the same utility, $\mathrm{X}_{11}$ balances can be used for another.

The concept of bliss point implies that there is only an extreme point which is the maximum in its utility function. This law is consistent with the law of diminishing marginal utility. In reality, all kinds of goods for people meet with the characteristics of bliss point.
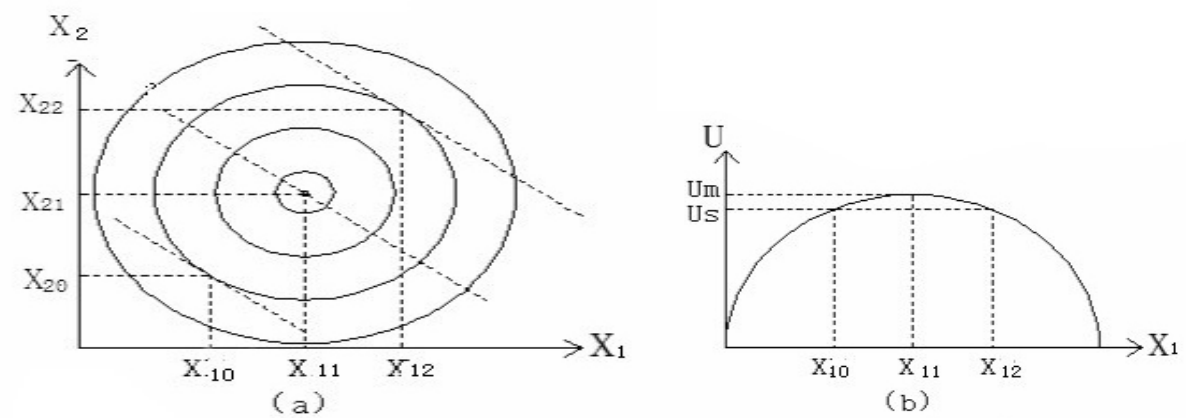

Fig. 1-Bliss point

\subsection{The law of demand}

The law of demand is that assuming that all the other conditions unchanged, the price of any commodity declines, the demand is bound to rise. This implies that under the condition of other conditions remaining unchanged, the commodity demand of a rational person is increased with a decline in commodity prices. The price is variable, and the demand is the dependent variable, the price being the only factor to cause the change of the demand. The demand curve indicates the quantity of goods demanded at each price. The demand curve is a curve that shows the relationship between price and demand, which is a table or curve of the amounts of goods that the buyer is willing to buy at each price level when other conditions are the same.

\section{Bliss point and Demand Curve}

In order to discuss the relationship between utility and demand, as well as the relationship between demand and price, we choose the most common example of the relationship between yield and fertilizer application of Spring Wheat. We put the consumer's utility as the yield of spring wheat (Yield is equal to yield multiplied by the price). The relationship between yield and $\mathrm{N}$ fertilizer application amount of spring wheat is equal to the utility function of wheat farmers. In the early stage of fertilization, more fertilizer is more conducive to the growth of crops. When the amount of $\mathrm{N}$ fertilizer reaches a certain point, the growth of spring wheat is at their best. But the increase in $\mathrm{N}$ fertilizer is harmful to crops greater than the benefits. The extra fertilizer not only has no effect on the growth of the crops, but also can even make the crops wither and die. Xue Zhengping, Yang Xingwei, Duan Xiangsuo ${ }^{7}$ studied on fertilizer. 
They concluded that "1987 2002 Nuanquan farm fertilizer use amount of pure N and spring wheat yield relationship (98\% confidence level) showed that the yield of spring wheat showed a parabola with $\mathrm{N}$ increased, the optimal amount of $\mathrm{N}$ is $300 \mathrm{~kg} / \mathrm{HM}$ (Fig. 2.)”.

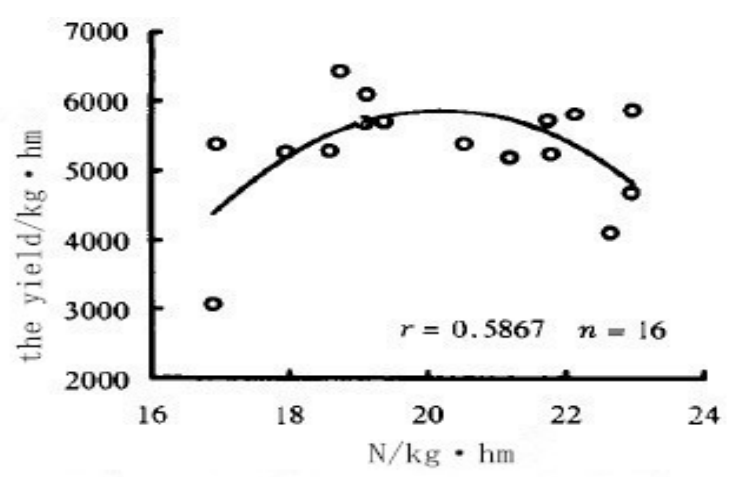

Fig. 2- Relationship between the Yield and N

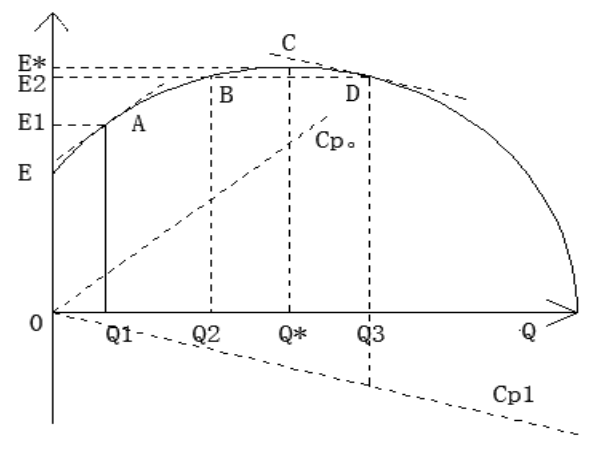

Fig. 3-Relationship of Yield ,N and Price

\subsection{Hypothesis}

In order to analyze and understand, we assume that the price of spring wheat is unchanged. The following analysis is based on the following assumptions. Firstly, Farmers have the ability to apply fertilizer to spring wheat based on the standard of maximum economic benefit and the relationship between yield and $\mathrm{N}$ fertilizer application amount and price changing. Secondly, we do not consider the temperature, the fertile degree of land, water and other factors on the yield of spring wheat. The price of $\mathrm{N}$ fertilizer is the only factors affecting the yield of Spring Wheat. Thirdly, the price of fertilizer is not influenced by the change of farmers 'purchasing volume. The relationship between the yield of spring wheat and the $\mathrm{N}$ fertilizer has a parabolic relationship. Fourthly, the yield of spring wheat and $\mathrm{N}$ fertilizer application amount of the relationship function is to open the downward parabola, with the maximum value $\left(\mathrm{Q}^{*}, \mathrm{E}^{*}\right)$, where $\mathrm{E}^{*}, \mathrm{Q}^{*}$ are greater than zero. That is to say, $\mathrm{E}=\mathrm{f}(\mathrm{q}), \mathrm{F}^{\text {“ }}(\mathrm{q})$ $<0, \mathrm{q}>0$, and you can refer to Fig. 3 .

Based on the assumption that: $\mathrm{N}$ fertilizer is a commodity, buying $\mathrm{N}$ fertilizer is the existence of purchasing costs C.C $=\mathrm{p}^{*} \mathrm{q}$ ( $\mathrm{P}$ for the price of $\mathrm{N}$ fertilizer, $\mathrm{N}$ for $\mathrm{Q}$ fertilizer demand). $\mathrm{E}$ for spring wheat yield $E=f(q) \cdot R$ is the net income of farmers, $R=E-C=f(q)-p^{*} q$. In order to maximize economic returns, so that the first derivative of $\mathrm{R}(\mathrm{q})$ is zero, and the maximum value of the function is that $R^{\prime}=f^{\prime}(q)-p=0, f^{\prime}(q)=p$. Then it can be concluded that the relationship between demand and price function. In other words, $q$ is the anti-function of $\mathrm{p}$, $q=f^{-1}(p)$. The optimal value of the economic income of farmer is the maximum value of $R$. Geometric interpretation: when the price is $\mathrm{C}_{\mathrm{p} 0}$, tangent point $\left(\mathrm{Q}_{1}, \mathrm{E}_{1}\right)$ A of $\mathrm{C}_{\mathrm{p} 0}$ and cost curve is extremum of function $\mathrm{R}$. That is to say, $\mathrm{Q}_{1}$ is the optimal amount of fertilize $\mathrm{E}_{1}$ for maximum yield.

\subsection{When $p=C_{p 0}\left(C_{p 0}>0\right)$, the relationship between $R$ and $E$.}

When $\mathrm{p}=\mathrm{Cp} 0 \quad(\mathrm{Cp} 0>0)$, the optimal amount of fertilizer is $\mathrm{Q}_{1}$, the yield of 
$\mathrm{R}\left(\mathrm{Q}_{1}\right)=\mathrm{f}\left(\mathrm{Q}_{1}\right)-\mathrm{Cp}_{0} * \mathrm{Q}_{1}=\mathrm{E}_{1}-\mathrm{Cp}_{0} * \mathrm{Q}_{1}$. When prices fall, the slope of the cost curve will be reduced, then point $\mathrm{Q}_{1}$ moves to the right and the demand $\mathrm{Q}$ will increase. When the price $\mathrm{P}$ is close to zero, the tangent slope of yield close to zero, and Q will reach $\mathrm{Q}^{*}$, figure 3. Therefore, the demand for $\mathrm{N}$ fertilizer is increasing with the decrease of the price. On the contrary, the demand of $\mathrm{N}$ fertilizer decreased with the increase of the price, and the demand and the price were negatively correlated.

\subsection{When $p=C_{p 0}\left(C_{p 0}=0\right)$, the relationship between $R$ and $E$.}

The cost of $\mathrm{N}$ fertilizer is zero means the price is zero, namely the cost curve slope is zero, the maximum number of yield function being exactly equal to satiation point. Under such conditions, $\mathrm{N}$ fertilizer belongs to the free goods, but non commodities, such as, water, light and temperature, etc...Based on the above assumptions and analysis, rational farmers he will choose the optimal amount of $\mathrm{Q}^{*}$, rather than the other. Because the amount of $\mathrm{Q}^{*}$ points will give farmers the greatest yield $\mathrm{E}^{*}$. $\mathrm{N}$ fertilizer is greater than or less than $\mathrm{Q}^{*}$ that will make the spring wheat yield decreased. For example, spring wheat optimum temperature is 25 degrees Celsius, farmers apparently do not set the temperature that is greater than or less than 25 degrees Celsius. He will choose the optimal temperature setting temperature (25 degrees Celsius) for Spring Wheat. Therefore, when the price is zero, the demand for goods is the most effective point. That is to say, the demand for commodities is equal to the number of Bliss point. Unfortunately, without consideration of costs or negligible events or goods, it is not concerned by the field of economics.

\subsection{When $p<C_{p 0}\left(C_{p 0}=0\right)$, the relationship between $R$ and $E$.}

When the cost of $\mathrm{N}$ fertilizer is less than zero, which means that the price is taken negative 。

The farmers will get extra income that is the negative cost of applying $\mathrm{N}$ fertilizer。 When $\mathrm{p}=\mathrm{C}_{\mathrm{p} 1}\left(\mathrm{C}_{\mathrm{p} 1}<0\right)$, the net income of farmers. $\mathrm{R}\left(\mathrm{Q}_{3}\right)=\mathrm{f}\left(\mathrm{Q}_{3}\right)-\mathrm{C}_{\mathrm{p} 1} * \mathrm{Q}_{3}=\mathrm{E}_{2}-\mathrm{C}_{\mathrm{p} 1} * \mathrm{Q}_{3}$. This kind of circumstance is special, extremely rare. In order to encourage the country to encourage consumption of a commodity, the state gives incentives or companies in order to promote a certain kind of goods, to spend money to please people.

\section{Giffen phenomenon}

\subsection{The origin of Giffen phenomenon.}

In mid eighteenth Century, the British economist Giffen put forward the concept of Giffen goods. In 1845, Ireland was attacked by an unknown disease. Until September 1846, about $3 / 4$ of the potatoes were destroyed. The price of potatoes that most people need in their daily life was increasing, however, the demand was still increasing. Robert Giffen observed this phenomenon and found that this phenomenon is contrary to the demand theorem. In order to commemorate him, the phenomenon of the relationship between demand and price is positive correlation has been named as Giffen phenomenon and goods with a positive correlation 
between demand and price is named Giffen goods. Some scholars believe that the law of demand can`t explain the Giffen mystery and they regard it as a kind of exception of demand theorem.

\subsection{The guesses of Giffen phenomenon}

Based on the environment at that time, we give the following several kinds of conjecture. Firstly, the number of the actual purchase of potato had not increased. Because the import of potato could not be more than the usual at that time. Even without taking into account the stock of the potato, the number of supply on the market can`t be greater than the amount of the disaster before the disaster. Secondly, the Giffen mystery were only considered the part of the region, or just to observe the phenomenon of some areas, which means that there was an increase in the demand for potatoes in some places, then the demand for potatoes in another place must be reduced. Thirdly, the change in demand for potatoes is caused by the price or other factors, such as natural disasters, changing in income, the reduction of food variety. Fourthly, the price of the substitute may have changed.

\subsection{The essence of Giffen phenomenon}

The law of demand is that the economic participation of people only considers the impact of price on demand in the case of other conditions unchanged. But in the real world, there are many factors that influence the demand, and the price is just one of the most important factors.

About the Giffen mystery, natural disasters changed consumer demand. For some consumers, the demand for potatoes had increased. But for some people, the demand for potatoes had reduced. The former may have the ability to buy a higher price of food before the natural disaster, but they could not afford the high price of food. Because their income could be increased after the natural disaster, thus they turn to buy a relatively low price of potatoes. While the latter had a low income as usual and taken the low price of potatoes as the staple food. When the scourge came, potato prices moved up, the original potato consumption was no longer their best choice, and these consumers will turn to seek lower prices of food. In one area where the first type of consumers accounted for a larger proportion, these consumers in the area would increase their purchase amount with potato prices moved up. Therefore, Robert Giffen observed the phenomenon that may in somewhere the first category of consumer was concentrated, so this type of consumers would increase their purchase amount of potatoes as long as the price rise was less than the cost of the purchase of other foods. Therefore, there would be phenomenon the actual purchase amount increases with the price rising.

\section{Conclusion}

This paper mainly draws the following conclusions. First, rational people make their own choices best according to the prevailing environment, known information, their own standards 
of measurement and decision-making thinking. In fact, in the face of the same information, every person has his own ability that accepts the information, the standard of measurement and decision-making thinking. So, why does each economist have different views on the same issue. Secondly, all the goods have bliss point for consumers, and utility function with bliss point has only one extreme value that is of great value. Thirdly, the demand theorem is that the price is only factor affecting the demand. That is to say, in the case of other factors that are constant and bliss point does not exist, changing in prices caused by changing in demand, which have a negative relationship. Finally, Giffen phenomenon rather than Giffen goods. Giffen phenomenon is to introduce other factors that may be the factors that affect the price, but also may be the factors that affect the demand. In the presence of these factors, the relationship between demand and price becomes more complex, is no longer a simple positive correlation. Therefore, we cannot consider the Giffen phenomenon is a special case of the law of demand, but is the general application of demand theorem. Therefore, the concept of Giffen goods is not very accurate.

\section{Reference}

1. W.C.Zhang, The economic explanation volume: Science said demand (China revised edition) [M]. Beijing: CITIC publishing house, 2010.6

2. Z. Wang, Law of demand and the phenomenon of Giffen [J]. Zhejiang social science, 2003 (4): 42-44.

3. H. Su, L. Yang, Reasonable economic man hypothesis rationality new exploration [J]. Journal of Henan Normal University (Philosophy and Social Science Edition), 2011, 38 (4): 51-54.

4. C.Q.Zhu, Y.H. Ding, On the revision of the rational man hypothesis of Chicago law and economics. [J]. Lanzhou journal, 2010 (7): 124-127

5. Y. Hanoch, "Neither an Angel nor an ant": Emotion as an aid to bounded rationality[J]. Journal of Economic Psychology, 2002, 23(1):1-25.

6. H. R. Varian, Intermediate Microeconomics: A Modern Approach (8th Edition), Shanghai people's press, p.034

7. Z.P. Xue, X.W. Yang, X.S.Duan, et al., Study on the relationship between soil nutrients and yield of spring wheat and optimal fertilizer application [J]. Chinese Journal of ecological agriculture, 2004, 12 (4): 110-112. 